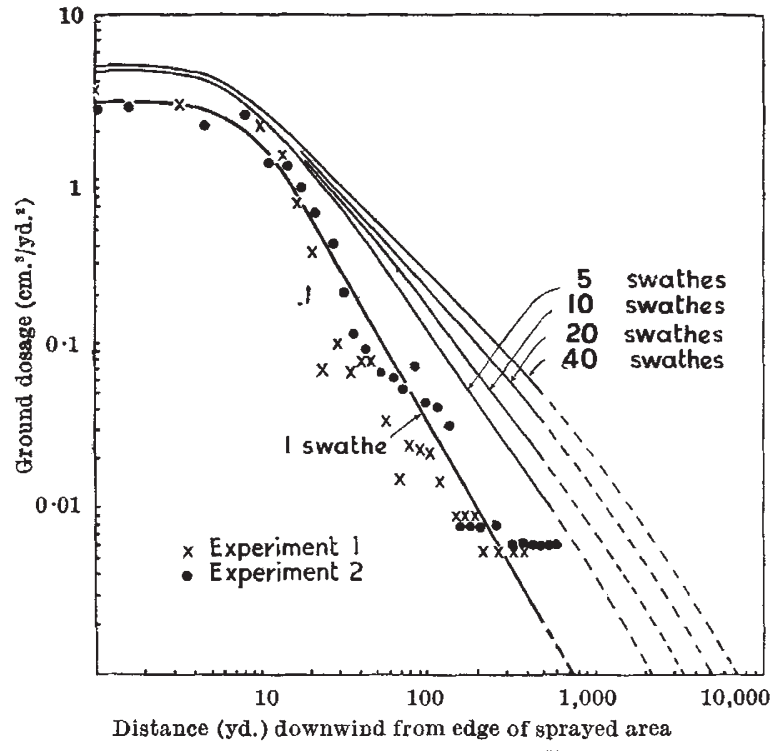

Fig. 1. The variation in ground dosage with distance downwind

example, applications of herbicides in crops, and, using this swathe width and the basic graphs of Figs. $l$ and 2, the build-up of dosages has been calculated for various distances downwind from the downwind edge of areas subjected to $5,10,20$, and 40 successive swathes. An increase in the number of swathes from 1 to 5 increases the ground deposit and the airborne concentration at the downwind edge of the target area by about twice, but a further increase in the number of swathes to 40 results in only a slight further increase. At $100 \mathrm{yd}$. downwind the swathes are still not additive, the hazard from 40 swathes being only 8-10 times that of one; at 1,000 yd. the hazard from 40 swathes is about 30 times that of one swathe, while it may be inferred that at $10,000 \mathrm{yd}$. the swathes would be nearly additive, in any event for an involatile liquid.

The results indicate the hazards to be expected for distances of up to a mile or so downwind from a

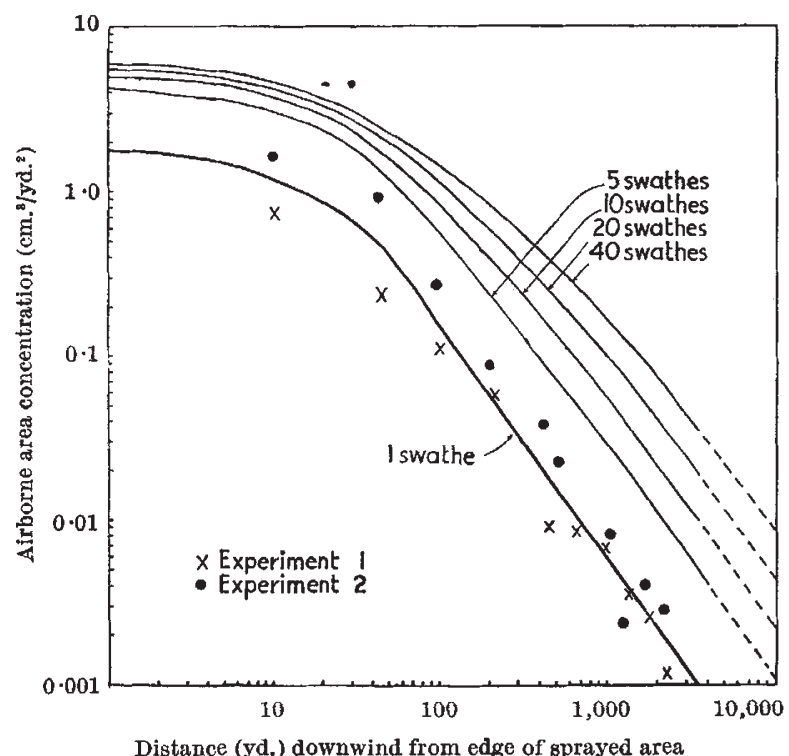
Fig. 2. The variation in airborme concentration with distance sprayed area. It would be more generally useful to extend the sampling for a few miles downwind, and it is hoped that this will be possible. Variations in droplet size and meteorological conditions are likely to have an effect upon dosage distributions, and their influence is being investigated.

Colonial Pesticides Research Unit, Arusha, Tanganyika.

* On leave from the University of California, Fulbright Assignment.

1 May, K. R., J. Sci. Instr., 22, 187 (1945).

${ }^{2}$ Yeo, D., and Thompson, B. W., Nature, 172, 168 (1953).

\section{World Variation in Annual Rainfall}

THE following analysis is based on the figures given by Conrad ${ }^{1}$ which cover 358 stations in the belt $60^{\circ} \mathrm{N},-60^{\circ} \mathrm{S}$. The aim of the work was to test the validity of the statement frequently quoted that rainfall variation is much greater in the tropics than in the temperate regions. The broad result of the investigation shows that this is not strictly true.

Conrad has used the mean deviation as the variance factor, $v_{a}$, relating this to $p$, the mean annual precipitation, so that $v_{a} / p=v_{r}$. First, the stations were zoned within $20^{\circ}$ belts and the differences of the mean of $v_{r}$ examined.

Table 1. Values of Probability versus Difference of Means of $v_{r}$

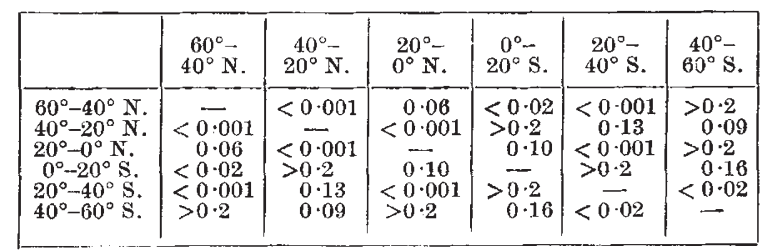

Table I shows the probability values obtained, and makes clear the fact that there is no significant difference between areas symmetrically placed north and south of the equator. It was therefore permissible to add the respective zones.

\begin{tabular}{|c|c|c|c|c|c|}
\multicolumn{9}{c|}{ Table 2 } \\
\hline & $\begin{array}{c}\text { Mean of } \\
v_{\boldsymbol{r}}\end{array}$ & $\begin{array}{c}\text { Variance } \\
\text { of } v_{\boldsymbol{r}}\end{array}$ & $\begin{array}{c}\text { Mean } p \\
(\mathrm{~mm} .)\end{array}$ & $\tau_{\boldsymbol{r}}$ calculated & $n$ \\
\hline $60^{\circ}-40^{\circ} \mathrm{N}$. & & & & & \\
and S. & $15 \cdot 5$ & $22 \cdot 0$ & 799 & $17 \cdot 0$ & 125 \\
$40^{\circ}-20^{\circ}$ & $22 \cdot 9$ & $110 \cdot 9$ & 958 & $16 \cdot 5$ & 154 \\
$20^{\circ}-0^{\circ}$ & $19 \cdot 3$ & $128 \cdot 8$ & 1,936 & $15 \cdot 0$ & 79 \\
\hline
\end{tabular}

From Table 2 it can be shown that the mean of the $40^{\circ}-20^{\circ}$ belt is significantly higher than the other belts, and that $20^{\circ}-0^{\circ}$ is higher than $60^{\circ}-40^{\circ}$. Conrad has derived an equation connecting $v_{r}$ and $p$, and from this $v_{r}$ was calculated. Columns 1 and 4 in Table 2 stress the fact that it is within the sub-tropics that annual rainfall variation is the greatest.

It was, unfortunately, not possible to test differences of $v_{r}$ within narrow annual rainfall groups, as the number of stations was too few ; but a detailed analysis will soon be made using European and African stations.

\section{J. F. GRIFHITHS}

East African Meteorological Department, Nairobi, Kenya. Nov. 8.

1 Monthly Weather Rev., 69, 5 (1941). 